- Previous studies have shown that educational outreach visits (academic detailing) can reduce inappropriate prescribing by medical practitioners.

- This study sought to assess whether academic detailing combined with printed educational material could be used to reduce antibiotic prescribing by dentists for acute dental pain.

- Evidence based guidelines for the use of antibiotics and analgesics for acute dental pain were produced.

- Antibiotic prescribing by general dental practitioners for acute dental pain can be reduced using academic detailing combined with guidelines. Guidelines alone do not affect antibiotic prescribing. care setting

\author{
J. M. Seager, ${ }^{1}$ R. S. Howell-Jones, ${ }^{2}$ F. D. Dunstan, ${ }^{3}$ M. A. O. Lewis, ${ }^{4}$ S. Richmond ${ }^{5}$ and D. W. Thomas ${ }^{6}$
}

\begin{abstract}
Objective To assess the effect of educational outreach visits on antibiotic prescribing for acute dental pain in primary care.

Study design Randomised controlled trial (RCT).

Setting General dental practices in four health authority areas in Wales. Subjects and methods General dental practitioners were recruited to the study and randomly allocated to one of the three study groups (control group, guideline group or intervention group). Following the intervention, practitioners completed a standardised questionnaire for each patient that presented with acute dental pain.

Interventions The control group received no intervention. The guideline group received educational material by post. The intervention group received educational material by post and an academic detailing visit by a trained pharmacist. The educational material included evidencebased guidelines on prescribing for acute dental pain and patient information leaflets.
\end{abstract}

Main outcome measures The number of antibiotic prescriptions issued to patients presenting with dental pain and the number of 'inappropriate' antibiotic prescriptions. Antibiotics were considered to be inappropriate if the patient did not have symptoms indicative of spreading infection. Results A total of 1,497 completed questionnaires were received from 23, 20 and 27 general dental practitioners in the control, guideline and intervention group respectively. Patients in the intervention group received significantly fewer antibiotic prescriptions than patients in the control group (OR $(95 \% \mathrm{Cl}) 0.63(0.41,0.95))$ and significantly fewer inappropriate antibiotic prescriptions (OR $(95 \% \mathrm{CI}) 0.33(0.21,0.54))$. However, antibiotic and inappropriate antibiotic prescribing were not

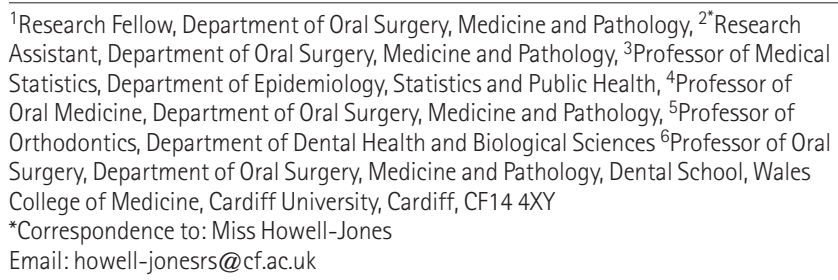

\section{Refereed paper}

Accepted 10 November 2005

DOI: $10.1038 /$ sj.bdj.4813879

๑ British Dental Journal 2006; 201: 217-222 significantly different in the guideline group compared to the control group (OR $(95 \% \mathrm{Cl}) 0.83(0.55,1.21)$ and $\mathrm{OR}(95 \% \mathrm{Cl}) 0.82$ $(0.53,1.29)$ respectively).

Conclusions Strategies based upon educational outreach visits may be successfully employed to rationalise antibiotic prescribing by dental practitioners.

\section{BACKGROUND}

The management of acute dental pain is primarily based upon an operative intervention, such as placement of a restoration, extraction of a tooth or extirpation of the dental pulp. Despite the general acceptance that antibiotic therapy is inappropriate as a primary treatment of pain associated with inflammation of the dental pulp, ${ }^{1}$ antibiotics are frequently prescribed for this condition: a study of 1,069 patients in Cheshire attending emergency dental clinics found $74 \%$ of patients with pulpitis were issued with an antibiotic prescription without any surgical intervention. ${ }^{2}$ Furthermore, a previous study undertaken in Cardiff demonstrated that $12 \%$ of 500 consecutive patients attending a hospital emergency dental clinic were taking antibiotics at the time of presentation. ${ }^{3}$ Moreover, 57\% of these patients had received antibiotics in the absence of an appropriate clinical indication. In addition to the over-prescription of antibiotics for acute dental conditions, it has also been demonstrated that there are wide variations in the type of antibiotic, frequency, dose and duration of the therapy prescribed..$^{3-5}$

Inappropriate antibiotic usage, in addition to being an unnecessary cost, exposes the patients to the risk of adverse effects and may contribute to the emergence of antibiotic-resistant organisms in the community. It is, therefore, imperative that strategies are developed to improve antibiotic prescribing for acute dental conditions in the primary care setting by general dental practitioners (GDPs).

A Cochrane review has been published that examined the impact of printed educational material on the quality and costeffectiveness of prescribing and concluded that the distribution of educational material alone appears to have little effect on prescribing behaviour. ${ }^{6}$ However, other studies suggest that the distribution of educational material followed by outreach visits using a trained person (academic detailer) to meet face-to-face with the 
health professional can be effective. ${ }^{7,8}$ The role of the academic detailer is to reinforce the educational material and emphasise alternatives to the prescription of a particular drug or group of drugs. ${ }^{9-11}$ This type of intervention is often referred to as academic detailing and examples of its previous use include interventions to reduce use of benzodiazepines, ${ }^{12}$ inappropriate antibiotics, ${ }^{13-15}$ and non steroidal anti-inflammatory drugs, ${ }^{16,17}$ and to improve antidepressant prescribing in the elderly. ${ }^{18}$

Patient expectation is an often cited explanation for the overprescription of antibiotics in medical practice. ${ }^{19,20}$ Antibiotic use, however, is only one of the reasons for patient attendance; symptomatic relief and an explanation of the disease process are equally important. ${ }^{21}$ Intervention strategies, via educational material, targeted at patients using primary care services have been shown to reduce inappropriate prescribing. ${ }^{7,22}$

The aim of this study was to rationalise unnecessary and inappropriate antibiotic prescribing for dental conditions in the primary care setting. A randomised controlled trial was undertaken to test the effectiveness of interventions involving academic detailing visits and patient-mediated educational material, in changing prescribing habits for acute dental conditions. The objectives of this project were to determine a rationale for antibiotic prescribing for acute dental conditions, inform GDPs and patients regarding appropriate prescribing habits and to assess the change in prescribing habits as a result of active patient-mediated and practitioner-mediated programmes.

\section{METHODS}

\section{Study design and setting}

The study was a randomised controlled trial involving primary care GDPs in four health authority areas in Wales (Bro Taf, Iechyd Morganwg, Dyfed Powys and Gwent). One practitioner from each practice that provided services under the NHS was initially eligible to participate. However, prior to randomisation, practitioners volunteering to participate who were also registered as working at another practice from which a GDP had already enrolled in the study, were excluded. This exclusion was undertaken to reduce the risk of cross-group contamination. Figure 1 shows the recruitment and flow of practitioners through the study. Practices were stratified prior to randomisation by their previous level of antibiotic prescribing (data from Health Solutions Wales) and Health Authority. Stratified randomisation was then undertaken in the Department of Epidemiology, Statistics and Public Health, Wales College of Medicine (using a computer program developed in-house) and practices assigned to one of three groups: control group, guideline group and intervention group. Practitioners in the intervention group received printed educational material by post and an academic detailing visit, practitioners in the guideline group received educational material by post with no academic detailing visit and the control group received no intervention. Ethical approval for the study was obtained from MREC for Wales and the respective Local Research Ethics Committees.

\section{The educational package}

The educational package consisted of guidelines for the management of acute dental pain, a laminated page summary of the recommendations and patient information leaflets. The primary aim of the guidelines was to reduce the inappropriate prescribing of antibiotic therapy. However, the guidelines also included recommendations for the prescribing of analgesics and information on emergency dental services in each local health authority.

The guidelines were developed in consultation with five GDPs and three general medical practitioners. Medline, EmBase, DARE, the National Research Register, the Oxford Pain Relief Database and the Cochrane library were searched for systematic reviews, randomised controlled trials and other relevant papers to ensure the guidelines were as evidence-based as possible. This was supplemented by a review of the bibliographies of recent reviews and backed up by the expert knowledge of a consultant oral microbiologist. The guidelines were reviewed by an external consultant in oral microbiology and by the Regional Pharmaceutical Advisors and Directors of Dental Public Health in the four health authorities involved in the study.

An information leaflet was designed for patients with acute dental pain that provided details of dental services (including emergency services in the relevant health authority) and pain relief. Most importantly, the leaflet also explained that antibiotics are not usually required for such a condition. The readability of the leaflet was assessed using the Gunning Fog Index test and the Fog reading score found to be nine years. The leaflet was reviewed by external referees, as described above for the guidelines, as well as by the Health Promotion Division in the National Assembly for Wales and eight lay people. The lay people were recruited from the Cardiff Dental Hospital Examination and Emergency Clinic waiting room and their views elicited using two focus group discussions facilitated by an experienced moderator. Clinicians and lay people involved in the development phase of the study did not participate in any other part of the main study.

\section{Intervention}

The educational package was posted to practitioners in the guideline group and the intervention group. Each practitioner in the intervention group was then visited by the academic detailer (a pharmacist who had been closely involved with the development of the guidelines) to discuss the content of the guidelines and encourage the rational use of antibiotics and analgesics when managing acute dental pain. The academic detailer was trained in interpersonal skills and selling techniques by a consultant experienced in training pharmaceutical company representatives. This enabled the promotion of the guidelines to be tailored according to the particular attitudes of each practitioner. The academic detailer was blind to the level of antibiotic prescribing (high, medium or low) of the practices being visited.

\section{Data collection}

The effect of the intervention was evaluated using a dental pain questionnaire which practitioners were asked to complete every time an adult (aged over 16 years) presented with acute dental pain. Information relating to the age, gender and registration status of the patient, presenting complaint, findings on examination, dental treatment and advice given, antibiotics or analgesics prescribed or recommended was collected. The questionnaire was piloted in Cardiff Hospital Examination and Emergency Clinic. Practitioners in the guideline and intervention groups were asked to complete the questionnaires after receipt of the guidelines and academic detailing visit respectively.

In order to assess whether patients who had not received an antibiotic were as satisfied with their treatment as patients who had received an antibiotic, a patient satisfaction questionnaire was developed to use as a CATI (Computer Assisted Telephone Interview). Practitioners were required to obtain each patient's consent before returning the dental pain questionnaire with the patient's telephone number. It was hoped that 10\% of patients would be systematically sampled throughout the study period and contacted. However, many practitioners reported that obtaining patient consent was time consuming and as a result, the rate of return of questionnaires was slow. This part of the study was therefore discontinued after contacting 156 consecutive patients. Patients were excluded if they could not be contacted within two weeks of their visit. 


\section{Data analysis}

The main outcome measures analysed were the number of antibiotic prescriptions issued for patients presenting with acute dental pain and the number of inappropriate antibiotic prescriptions. Antibiotics were considered to be inappropriate if the patient did not have facial swelling, lymphadenopathy, limited mouth opening, raised temperature, difficulty swallowing or acute necrotising ulcerative gingivitis (ANUG).

The data collected from the study were entered and analysed in SPSS, while more advanced multilevel modelling was carried out in MLWiN. Direct comparisons were made between the control, guideline and intervention groups using the Chi-square test, one-way ANOVA or Kruskal-Wallis test but the main analysis, to assess the effect of the intervention on prescribing and to identify other factors which may influence prescribing, was carried out using multilevel logistic regression to allow for withinpractice clustering. $\mathrm{P}$ values of $<0.05$ were considered to be statistically significant.

\section{Sample size}

Practice, not practitioner, was the unit of randomisation and the sampling was, therefore, a form of cluster sampling. The intraclass correlation co-efficient was considered in the sample size calculation since correlation between different patients from the same practice inflates the required sample size. The intraclass correlation coefficient was estimated from baseline data to be 0.04 . The study hoped to recruit 30 GDPs into each arm of the study and to obtain data on 30 patients from each GDP. This sample size was chosen to have $90 \%$ power for detecting a change of one third in the prescribing rate of antibiotics, from $28 \%$ to $18 \%$.

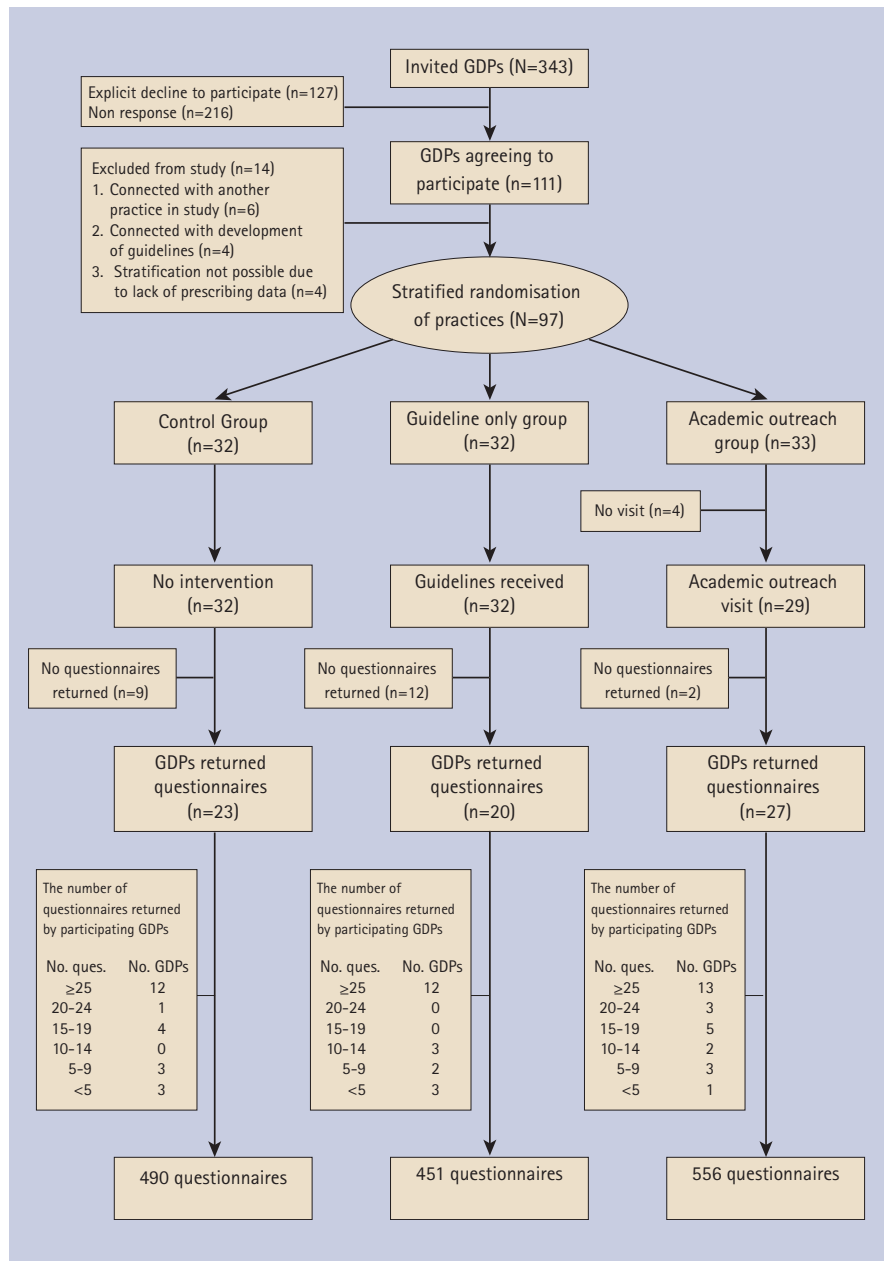

Fig. 1 Flowchart of GDP participation and study design

\section{RESULTS}

Initially, 97 GDPs agreed to take part in the study, however, following randomisation, 27 practitioners dropped out (Fig. 1). Completed questionnaires were received from 23, 20 and 27 practitioners in the control, guideline and intervention group respectively. The characteristics of the dental practitioners who returned questionnaires, shown in Table 1, were found to be very similar in the different arms of the study.

In total, 1,584 questionnaires were received from GDPs, of which 87 had to be excluded as patients were under 16 years of age. Therefore 1,497 questionnaires were analysed: 490, 451 and 556 questionnaires from the control, guideline and intervention groups respectively. The characteristics of the patients are shown in Table 1 . The age and gender of patients were evenly distributed between the groups but there were significantly more private registered patients in the intervention group than in the control and guideline group (Chi-square test, $\mathrm{P}<0.001$ ).

Presenting complaint and findings on examination are shown in Table 2. There were significantly more patients with a symptom indicative of spreading infection (facial swelling, lymphadenopathy, limited mouth opening, raised temperature, difficulty swallowing or ANUG) in the intervention group than in the control group (24.5\% vs. $19 \%$, Chi-square test, $\mathrm{P}=0.03$ ). The intervention group and the guideline group, however, did not differ significantly $(24.5$ vs. $23.1 \%$, Chi-square test, $\mathrm{P}=0.60$ ). The number of patients with a symptom indicative of spreading infection decreased significantly with age (Chi-square test, $\mathrm{P}<0.05$ ). The proportions of patients who received dental treatment were $79.4 \%, 85.1 \%$ and $86.2 \%$ in control, guideline and intervention group respectively, while the proportions of patients who received advice in the control, guideline and intervention groups were 76.5\%, 71.8\% and 75.5\% respectively.

\begin{tabular}{|c|c|c|c|c|}
\hline & & \multicolumn{3}{|c|}{ Arm of study } \\
\hline & & Control & Guideline & Intervention \\
\hline \multicolumn{2}{|c|}{ Number of GDPs } & 23 & 20 & 27 \\
\hline \multirow{2}{*}{ Gender } & Male (\%) & 65 & 75 & 81 \\
\hline & Female (\%) & 35 & 25 & 18.1 \\
\hline \multicolumn{2}{|c|}{ Mean years since qualification } & $\begin{array}{l}19.4 \\
(S D 10)\end{array}$ & $\begin{array}{l}21.2 \\
(S D 8.2)\end{array}$ & $\begin{array}{l}22.1 \\
\text { (SD 8.6) }\end{array}$ \\
\hline \multicolumn{2}{|c|}{$\begin{array}{l}\text { Mean pop:wte in the LHB of } \\
\text { each practice }\end{array}$} & $\begin{array}{l}3724 \\
\text { (SD 735) }\end{array}$ & $\begin{array}{l}3927 \\
\text { (SD 818) }\end{array}$ & $\begin{array}{l}3938 \\
(\text { SD 924) }\end{array}$ \\
\hline \multicolumn{2}{|c|}{$\begin{array}{l}\text { Number }(\%) \text { of dentists with } \\
\text { post graduate qualifications }\end{array}$} & $3(13.0)$ & $1(5.0)$ & $4(14.8)$ \\
\hline \multicolumn{2}{|c|}{ Number of patients } & 490 & 451 & 556 \\
\hline \multicolumn{2}{|c|}{ Mean age (years) } & $\begin{array}{l}44.3 \\
\text { (SD 16.9) }\end{array}$ & $\begin{array}{l}43.7 \\
\text { (SD 16.2) }\end{array}$ & $\begin{array}{l}45.7 \\
\text { (SD 16.2) }\end{array}$ \\
\hline \multirow{2}{*}{ Gender } & Male $(\%)$ & 45 & 42 & 44 \\
\hline & Female (\%) & 55 & 58 & 56 \\
\hline \multirow{4}{*}{$\begin{array}{l}\text { Registration } \\
\text { Status }\end{array}$} & NHS (\%) & 75 & 70 & 65 \\
\hline & Private $(\%)$ & 8 & 8 & $20^{*}$ \\
\hline & $\begin{array}{l}\text { Not registered } \\
(\%)\end{array}$ & 16 & 20 & 15 \\
\hline & $\begin{array}{l}\text { Not specified } \\
(\%)\end{array}$ & 1 & 2 & 0 \\
\hline
\end{tabular}

Pop:wte Ratio of mean population to whole-time equivalent dentists LHB Local Health Board

* Significantly more privately registered patients in the intervention group than in the control and guideline group (Chi-square-test, $\mathrm{P}<0.001$ ). 


\begin{tabular}{|c|c|c|c|}
\hline & $\begin{array}{l}\text { Control } \\
\text { group } \\
n=490(\%) \\
\end{array}$ & $\begin{array}{l}\text { Guideline } \\
\text { group } \\
\mathrm{n}=451(\%)\end{array}$ & $\begin{array}{l}\text { Intervention } \\
\text { group } \\
\mathrm{n}=556(\%)\end{array}$ \\
\hline \multicolumn{4}{|l|}{ Presenting complaint } \\
\hline Toothache & $327(66.7)$ & 315 (69.8) & $377(67.8)$ \\
\hline Painful/infected gums & $129(26.3)$ & $107(23.7)$ & $122(21.9)$ \\
\hline Fractured filling & $34(6.9)$ & $29(6.4)$ & $26(4.7)$ \\
\hline Lost filling & $40(8.2)$ & $25(5.5)$ & $21(3.8)$ \\
\hline Broken filling & $72(14.7)$ & $70(15.5)$ & $44(7.9)$ \\
\hline Facial swelling & $53(10.8)$ & $65(14.4)$ & $79(14.2)$ \\
\hline Other & $5(1.0)$ & $1(0.2)$ & $4(0.8)$ \\
\hline \multicolumn{4}{|l|}{ Extraoral examination } \\
\hline Normal & 388 (79.2) & 328 (72.7) & $412(74.1)$ \\
\hline Swelling & $71(14.5)$ & $90(20.0)$ & $112(20.1)$ \\
\hline Lymphadenopathy & $54(11.0)$ & $47(10.4)$ & $71(12.8)$ \\
\hline Limited mouth opening & $25(5.1)$ & $29(6.4)$ & $39(7.0)$ \\
\hline Raised temperature & $11(2.2)$ & $13(2.9)$ & $11(2.0)$ \\
\hline Difficulty swallowing & $10(2.0)$ & $12(2.7)$ & $6(1.1)$ \\
\hline Other & $2(0.4)$ & $4(0.9)$ & $1(0.2)$ \\
\hline \multicolumn{4}{|l|}{ Intraoral examination } \\
\hline Caries & 135 (27.6) & $163(36.1)$ & $134(24.1)$ \\
\hline Lost/broken fillings & $110(22.4)$ & 75 (16.6) & $74(13.3)$ \\
\hline Tender teeth & $171(34.9)$ & $169(37.5)$ & $170(30.6)$ \\
\hline Loose teeth & $64(13.1)$ & $81(18.0)$ & $66(11.9)$ \\
\hline Recent fractured tooth & $58(11.8)$ & 40 (8.9) & $34(6.1)$ \\
\hline Abscess/pus discharge & $94(19.2)$ & $115(25.5)$ & $113(20.3)$ \\
\hline Gingival inflammation & $118(24.1)$ & 98 (21.7) & $106(19.1)$ \\
\hline ANUG & $7(1.4)$ & $3(0.7)$ & $5(0.9)$ \\
\hline Other & $2(0.4)$ & $4(0.9)$ & $10(1.9)$ \\
\hline $\begin{array}{l}\text { Percentage of patients } \\
\text { with a symptom of } \\
\text { spreading infection }\end{array}$ & $19.0 \%$ & $23.1 \%$ & $24.5 \%$ \\
\hline
\end{tabular}

In the analysis of antibiotic prescriptions there were two outcome measures: 1) all antibiotic prescriptions and 2) inappropriate antibiotic prescriptions. Inappropriate antibiotic prescribing was defined as the provision of an antibiotic to a patient who did not present with a symptom indicative of spreading infection. For all antibiotics, and also for inappropriate antibiotics, the differences between the groups were substantial. However, considerable variation occurred between practitioners within the three groups and, therefore, multilevel modelling was used to reflect the hierarchical data, with patients clustered within practitioners. Taking clustering into account, a 95\% confidence interval for the difference between the intervention and control groups was $(0.3 \%, 17 \%)$ for all antibiotic prescriptions while that for the difference between the guideline and control groups was $(-6.4 \%, 12.4 \%)$. The odds ratios (OR), comparing the chance of a patient being prescribed an antibiotic and an inappropriate antibiotic in the separate study groups are shown in Table 3. They were estimated using multilevel logistic

\begin{tabular}{l|l|l|l|l} 
Table 3 Antibiotic prescribing \\
\hline & \multicolumn{2}{|l|}{$\begin{array}{l}\text { Patients prescribed } \\
\text { antibiotics }\end{array}$} & \multicolumn{2}{|l}{$\begin{array}{l}\text { Patients prescribed } \\
\text { antibiotics inappropriately }\end{array}$} \\
\hline & $\%$ & OR $(95 \% \mathrm{Cl})$ & $\%$ & OR $(95 \% \mathrm{Cl})$ \\
\hline $\begin{array}{l}\text { Control group } \\
(\mathrm{n}=490)\end{array}$ & 32 & 1 & 18 & 1 \\
\hline $\begin{array}{l}\text { Guideline group } \\
(\mathrm{n}=451)\end{array}$ & 29 & $0.83(0.55,1.21)$ & 15 & $0.82(0.53,1.29)$ \\
\hline $\begin{array}{l}\text { Intervention group } \\
(\mathrm{n}=556)\end{array}$ & 23 & $0.63(0.41,0.95)$ & 7 & $0.33(0.21,0.54)$
\end{tabular}

Table 4 Influence of study group, patient and practitioner characteristics on antibiotic prescribing, explored using multivariate multilevel analysis.

\begin{tabular}{|c|c|c|c|}
\hline Factor & Unit of comparison & Odds ratio $(95 \% \mathrm{Cl})$ & P-value \\
\hline Prescribing & $\begin{array}{l}\text { Intervention vs. control } \\
\text { Guideline vs. control }\end{array}$ & $\begin{array}{l}0.59(0.57,0.93) \\
0.81(0.50,1.30)\end{array}$ & $\begin{array}{l}0.022 \\
0.40\end{array}$ \\
\hline $\begin{array}{l}\text { Age of } \\
\text { patient }\end{array}$ & Difference of 10 years & $0.82(0.76,0.89)$ & $<0.0001$ \\
\hline $\begin{array}{l}\text { Gender of } \\
\text { patient }\end{array}$ & Female vs. male & $1.07(0.84,1.36)$ & 0.58 \\
\hline $\begin{array}{l}\text { Type of } \\
\text { registration }\end{array}$ & $\begin{array}{l}\text { Private vs. NHS } \\
\text { Unregistered vs. NHS }\end{array}$ & $\begin{array}{l}1.41(0.90,2.20) \\
0.89(0.62,1.26)\end{array}$ & $\begin{array}{l}0.13 \\
0.50\end{array}$ \\
\hline $\begin{array}{l}\text { Gender of } \\
\text { GDP }\end{array}$ & Female vs. male & $1.02(0.63,1.61)$ & 0.93 \\
\hline $\begin{array}{l}\text { Postgraduate } \\
\text { qualification }\end{array}$ & Qualification vs. none & $0.51(0.26,1.01)$ & 0.05 \\
\hline $\begin{array}{l}\text { Years since } \\
\text { qualification } \\
\text { of GDP }\end{array}$ & $\begin{array}{l}<15 \text { against } 16-30 \\
<15 \text { against } \geq 30\end{array}$ & $\begin{array}{l}1.16(0.73,1.81) \\
1.36(0.76,2.41)\end{array}$ & $\begin{array}{l}0.53 \\
0.29\end{array}$ \\
\hline $\begin{array}{l}\text { Pop: wte in } \\
\text { LHB }^{*}\end{array}$ & $\begin{array}{l}\text { Medium vs. small } \\
\text { Large vs. small }\end{array}$ & $\begin{array}{l}1.23(0.77,1.93) \\
1.36(0.84,2.17)\end{array}$ & $\begin{array}{l}0.37 \\
0.21\end{array}$ \\
\hline $\begin{array}{l}\text { Pop:wte Ratio o } \\
\text { LHB Local Health } \\
{ }^{*} \text { The values of th } \\
\text { more than } 4000\end{array}$ & $\begin{array}{l}\text { nean population to whole-tin } \\
\text { Board } \\
\text { pop:wte were divided into } 3\end{array}$ & gories, up to 2500,250 & 00 , and \\
\hline
\end{tabular}

regression and show the chance of a prescription in the intervention group to be significantly lower than the control group.

The influence of both patient and practitioner characteristics on the tendency to prescribe was explored using multivariate multilevel analysis. Patient characteristics were age, gender and registration status, while the practitioner characteristics were gender, a postgraduate qualification, number of years since qualification and the population to whole-time equivalent dentists ratio (pop: wte) in the LHB of the dental practice. Table 4 shows the OR of an antibiotic prescription associated with different levels of each factor. The individual factors were included in a model one at a time in addition to the main factor of the study group.

The only factor other than the group that was statistically significant was age; younger patients were significantly more likely to receive antibiotics than older patients. Other factors showed interesting trends but these were not statistically significant. The variables for which the evidence of an association was weakest, namely the genders of patient and dentist, the years since qualification and the pop:wte levels, were left out of the model. The resulting model parameters were as shown in Table 5. Inappropriate prescribing was also modelled using multivariate multilevel logistic regression. In this analysis, none of the patient or practitioner factors, other than study group, was found to be significant, including patient's age. 


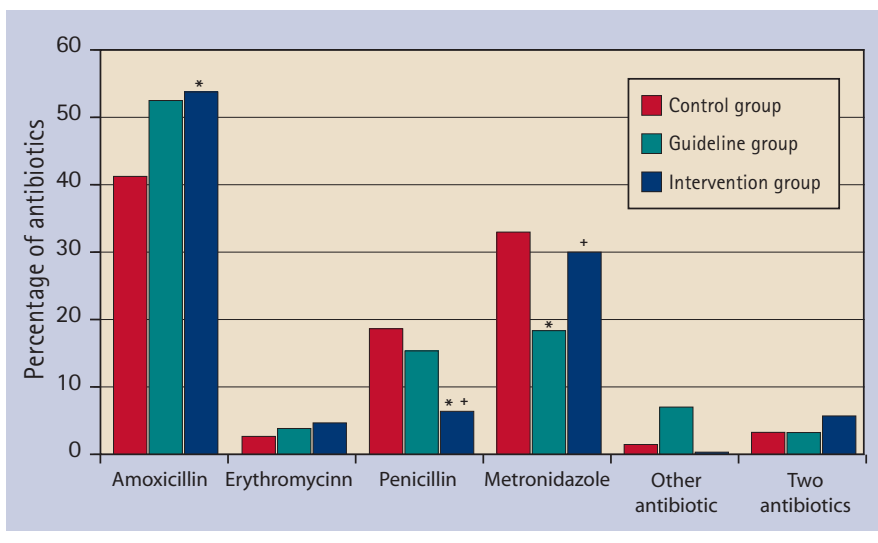

Fig. 2 The percentage of each antibiotic type prescribed by GDPs.

*Significantly different from the control group (Chi-square test, $\mathrm{P}<0.05$ );

+Significantly different from the guideline group (Chi-square test, $\mathrm{P}<0.05$ )

\begin{tabular}{|c|c|c|c|}
\hline Factor & Unit of comparison & $\begin{array}{l}\text { Odds ratio } \\
(95 \% \mathrm{Cl})\end{array}$ & P-value \\
\hline Prescribing & $\begin{array}{l}\text { Intervention vs. control } \\
\text { Guideline vs. control }\end{array}$ & $\begin{array}{l}0.62(0.40,0.97) \\
0.83(0.55,1.35)\end{array}$ & $\begin{array}{l}0.033 \\
0.47\end{array}$ \\
\hline Age of patient & Difference of 10 years & $0.82(0.76,0.89)$ & $<0.0001$ \\
\hline $\begin{array}{l}\text { Type of } \\
\text { registration }\end{array}$ & $\begin{array}{l}\text { Private vs. NHS } \\
\text { Unregistered vs. NHS }\end{array}$ & $\begin{array}{l}1.41(0.91,2.21) \\
0.89(0.62,1.26)\end{array}$ & $\begin{array}{l}0.12 \\
0.50\end{array}$ \\
\hline $\begin{array}{l}\text { Postgraduate } \\
\text { qualification }\end{array}$ & Qualification vs. none & $0.58(0.31,1.01)$ & 0.10 \\
\hline
\end{tabular}

Pop:wte Ratio of mean population to whole-time equivalent

The types of antibiotics prescribed are shown in Figure 2 and the duration of antibiotic treatment summarised in Table 6. The differences between the durations were not significant (Kruskal Wallis test, $\mathrm{P}>0.05$ ).

\section{Patient satisfaction survey}

A total of 156 patients were contacted, 89 of whom were from the control group and 67 from the guideline group. Twenty-nine of the patients in the control group and 16 in the guideline group had received a prescription for an antibiotic. Approximately 40\% of patients ( 36 from the control group and 25 from the guideline group) stated that they thought their dental problem was caused by an infection. However, only $23 \%$ of patients expected to get a prescription for an antibiotic, and only $26 \%$ of patients hoped for a prescription. Gender did not influence whether a patient hoped for an antibiotic prescription (Chi-square test, $\mathrm{P}>0.05$ ), however, there was a significant difference in the mean age of those patients that hoped for an antibiotic prescription (40.5 years) and those that did not (49.8 years), (t-test, $\mathrm{P}<0.05$ ). The majority of patients who had hoped for an antibiotic prescription did receive one: only six patients hoped for a prescription for an antibiotic but did not receive one but nine patients who did not want a prescription did receive one. Of those patients that did not receive an antibiotic, only three patients (all in the control group) answered that they were dissatisfied with the dentist's decision. In addition, there was no evidence that patients who had not received a prescription for an antibiotic were less likely to feel that the treatment

\begin{tabular}{llll}
\multicolumn{4}{l}{ Table $\mathbf{6}$ Duration of antibiotic treatment } \\
\hline & $\begin{array}{l}\text { Control group } \\
\mathbf{n}(\%)\end{array}$ & $\begin{array}{l}\text { Guideline group } \\
\mathbf{n}(\%)\end{array}$ & $\begin{array}{l}\text { Intervention } \\
\text { group } \mathbf{n}(\%)\end{array}$ \\
\hline Less than 3 days & $2(1)$ & $3(2)$ & $5(4)$ \\
\hline 3 or 4 days & $32(20)$ & $13(10)$ & $27(21)$ \\
\hline 5 days & $109(69)$ & $96(73)$ & $77(59)$ \\
\hline More than 5 days & $12(9)$ & $19(15)$ & $21(16)$
\end{tabular}

they had received had been effective, compared with patients who had received an antibiotic (Chi-square test, $\mathrm{P}>0.05$ ).

\section{Analgesic prescriptions or recommendations}

Analgesic prescribing was found to be significantly higher in the guideline $(22.8 \%$ of patients) and intervention $(20.3 \%$ of patients) groups than the control group (2.7\% of patients). However, the difference between the guideline group and the intervention group was not significant.

Antibiotics were used more frequently than analgesics by dentists in all three study groups. Patients prescribed antibiotics were not significantly more likely to be prescribed an analgesic in any of the study groups (OR (95\% CI) for control group 1.85 (0.61, $5.60)$, guideline group $0.95(0.58,1.54)$ and intervention group $1.56(0.98,2.54))$. Furthermore, fitting a multilevel model showed no significant interaction between study group and analgesic on antibiotic prescribing.

Ibuprofen was prescribed, or recommended, more than any other analgesic in all three study groups, with paracetamol being the second most frequently used analgesic. However, practitioners in the intervention group prescribed or recommended paracetamol significantly less than practitioners in the other two groups (Chisquared test, $\mathrm{P}<0.05)$.

\section{DISCUSSION}

Several studies have demonstrated that educational outreach visits can significantly affect prescribing, including antibiotic prescribing, by general medical practitioners. ${ }^{12-14,16,17,23,24}$ However, this is the first study, to our knowledge, to assess the effect of educational outreach visits on prescribing by GDPs. A significant reduction in the number of antibiotic prescriptions issued by dentists in the intervention group compared to dentists in the control and guideline groups was obtained following educational outreach visits by a pharmacist. The chance that dentists in the intervention group would write an antibiotic prescription for patients presenting with acute dental pain was approximately $70 \%$ that of dentists in the control group.

Factors such as patient gender and registration status were not found to significantly influence prescribing and neither did practitioner characteristics such as gender, number of years since qualification and ratio of the mean population to whole time equivalent dentist (pop:wte) in the local health board. The only factor that significantly influenced prescribing other than study group was age; younger patients were more likely to receive antibiotics than older patients. However, this could be because older patients were less likely to present with a symptom of spreading infection (facial swelling, lymphadenopathy, limited mouth opening, raised temperature, difficulty swallowing or ANUG) than younger patients. Indeed, there was also a significant reduction in the level of inappropriate antibiotic prescriptions in the intervention group compared to the control group, and here the age of the patient did not significantly affect inappropriate prescribing. The chance that dentists in the intervention group would write an inappropriate antibiotic prescription for acute dental pain was a third that of dentists in the control group. 
Analgesic prescribing was very low in all three groups and dentists were more likely to use an antibiotic than an analgesic. Many practitioners in the intervention group commented that dental pain is considerably reduced following dental treatment and they feel that analgesics are no longer required. It is not clear why analgesic prescribing was so much lower in the control group compared to the other two groups. Practitioners in the guideline and intervention groups used the non steroidal anti-inflammatory drug, ibuprofen, more often than any other analgesic, as recommended in the guidelines. Several studies have shown that non steroidal antiinflammatory drugs, such as ibuprofen, are more effective than paracetamol for relieving dental pain. ${ }^{25,26}$

Questionnaires were used to assess prescribing in order to collect diagnosis related data and to distinguish between antibiotics prescribed for the management of acute dental pain and antibiotics prescribed for prophylaxis. The fact that practitioners had to complete a questionnaire each time they saw a patient with acute dental pain might have focused the attention of practitioners in all three groups and thus reduced their prescribing. However, this would have reduced the possibilities of detecting prescribing differences in the study. Furthermore, information on antibiotic prescribing was not specifically requested and practitioners were not told that the study was about antibiotic prescribing. Details of all prescriptions were solicited and the guidelines included recommendations for analgesic prescribing as well as antibiotic prescribing.

The number of questionnaires returned in this study was lower than the a priori calculated sample size. The decreased numbers will have reduced the power of the study to identify any differences between the groups and will have led to wider confidence intervals for any effect sizes. However, the main comparison was statistically significant and the likely effect of a larger sample would have been to increase the precision with which the effect size was estimated. It is possible that some of the differences in the secondary outcomes may have been significant with the planned sample size but the main objective was achieved.

Medical practitioners' perception of patient expectation with regard to issuing antibiotic prescriptions, as well as patients' hopes, has been shown to be a strong determinant in the decision to prescribe. ${ }^{20}$ In this study, a small number of patients who had attended a general dental practitioner were surveyed to ascertain whether there was a high level of expectation for receiving an antibiotic. Only about one-quarter of patients said they hoped to receive a prescription for antibiotics. Furthermore, only 3\% of those patients who did not receive an antibiotic were dissatisfied with the dentist's decision.

\section{CONCLUSION}

The results from this randomised controlled trial suggest that evidence based guidelines alone do not improve prescribing by general dental practitioners. However, educational outreach visits by a pharmacist may be successfully employed to improve prescribing.

\section{Future research}

Studies need to be undertaken that address the durability of behaviour change following academic detailing, and assess methods for reinforcing guidelines and maintaining changes in clinical practice. Studies should also be undertaken to evaluate the impact of reductions in antibiotic prescribing by general dental and general medical practitioners on costs, outcomes and antibiotic resistance in the community.

This study was funded in full by a grant from the NHS National R\&D Programme on Primary Dental Care.

1. Olson A K, Edington E M, Kulid J C, Weller R N. Update on antibiotics for the endodontic practice. Compendium 1990; 11: 328-332.

2. Dailey $Y$ M, Martin M V. Are antibiotics being used appropriately for emergency dental treatment? Br Dent J2001; 191: 391-393.

3. Thomas D W, Satterthwaite J, Absi E G et al. Antibiotic prescription for acute dental conditions in the primary care setting. Br Dent J 1996; 181: 401-404.

4. Palmer N, Martin M. An investigation of antibiotic prescribing by general dental practitioners: a pilot study. Prim Dent Care 1998; 5: 11-14.

5. Roy K M, Bagg J. Antibiotic prescribing by general dental practitioners in the Greater Glasgow Health Board, Scotland. Br Dent J 2000; 188: 674-676.

6. Freemantle N, Harvey E L, Wolf F et al. Printed educational materials. Cochrane Database Syst Rev 2004; 2 .

7. Gill P S, Makela $M$, Vermeulen $\mathrm{K} M$ et al. Changing doctor prescribing behaviour. Pharm World Sci 1999; 21: 158-167.

8. Thomson O'Brien M A, Oxman A D, Davis D A et al. Educational outreach visits: effects on professional practice and health care outcomes. Cochrane Database Syst Rev 2000: 2.

9. Soumerai S B, Avorn J. Principles of educational outreach ('academic detailing') to improve clinical decision making. JAMA 1990; 263: 549-556

10. Bernal-Delgado E, Galeote-Mayor M, Pradas-Arnal F, Peiro-Moreno S. Evidence based educational outreach visits: effects on prescriptions of non-steroidal antiinflammatory drugs. J Epidemiol Comm Health 2002; 56: 653-658.

11. Freemantle N, Nazareth I, Eccles M et al. A randomised controlled trial of the effect of educational outreach by community pharmacists on prescribing in UK general practice. BrJ Gen Pract 2002; 52: 290-295.

12. Berings $D$, Blondeel $L$, Habraken $H$. The effect of industry-independent drug information on the prescribing of benzodiazepines in general practice. Eur $J$ Clin Pharmacol 1994; 46: 501-505.

13. Avorn J, Soumerai S B. Improving drug-therapy decisions through educational outreach. A randomized controlled trial of academically based 'detailing'. $N$ Engl J Med 1983; 308: 1427-1463.

14. Santoso B, Suryawati S, Prawaitasari J E. Small group intervention vs formal seminar for improving appropriate drug use. Soc Sci Med 1996; 42: 1163-1168.

15. Ilett K F, Johnson $S$, Greenhill $G$ et al. Modification of general practitioner prescribing of antibiotics by use of a therapeutics advisor (academic detailer). Br JClin Pharmacol 2000; 49: 168-173.

16. Stergachis $A$, Fors $M$, Wagner $E H$ et al. Effect of clinical pharmacists on drug prescribing in a primary-care clinic. Am J Hosp Pharm 1987; 44: 525-529.

17. Newton-Syms F A, Dawson P H, Cooke J et al. The influence of an academic representative on prescribing by general practitioners. Br J Clin Pharmacol 1992; 33: $69-73$.

18. van Eijk M E C, Avorn J, Porsius A J, de Boer A. Reducing prescribing of highly anticholinergic antidepressants for elderly people: randomised trial of group versus individual academic detailing. Br Med J 2001; 322: 1-6.

19. Britten N. Patients' demands for prescriptions in primary care. Patients cannot take all the blame for overprescribing. Br Med J 1995; 310: 1084-1085.

20. Britten $N$, Ukoumunne 0 . The influence of patients' hopes of receiving a prescription on doctors' perceptions and the decision to prescribe: a questionnaire survey. Br Med J 1997; 315: 1506-1510

21. Hamm R M, Hicks R J, Bemben D A. Antibiotics and respiratory infections: are patients more satisfied when expectations are met? J Fam Pract 1996; 43: 56-62.

22. Davis D A, Thomson M A, Oxman A D, Haynes R B. Changing physician performance. A systematic review of the effect of continuing medical education strategies. JAMA 1995; 274: 700-705.

23. McConnell T S, Cushing A H, Bankhurst A D et al. Physician behaviour modification using claims data: tetracycline for upper respiratory infection. West J Med 1982; 137: 448-450.

24. Coenen S, Van Royen P, Michiels B, Denekens J. Optimizing antibiotic prescribing for acute cough in general practice: a cluster-randomized controlled trial. J Antimicrob Chemother 2004; 54: 661-672.

25. Cooper S A, Schachtel B P, Goldman E et al. Ibuprofen and acetaminophen in the relief of acute pain: a randomized, double-blind, placebo-controlled study. J Clin Pharmacol 1989; 29: 1026-1030.

26. Barden J, Edwards J E, McQuay H J et al. Relative efficacy of oral analgesics after third molar extraction. Br DentJ 2004; 197: 407-411. 